\title{
Front Matter: Volume 11322
}

, "Front Matter: Volume 11322," Proc. SPIE 11322, XIV International Conference on Pulsed Lasers and Laser Applications, 1132201 (11 December 2019); doi: 10.1117/12.2556822

SDIE Event: XIV International Conference on Pulsed Lasers and Laser Applications (AMPL-2019), 2019, Tomsk, Russian Federation 


\title{
PROCEEDINGS OF SPIE
}

\section{International Conference on Pulsed Lasers and Laser Applications}

\author{
Victor F. Tarasenko \\ Anton V. Klimkin \\ Maxim V. Trigub \\ Editors
}

\section{5-20 September 2019 \\ Tomsk, Russian Federation}

\section{Organized by}

Institute of Atmospheric Optics (Russian Federation) • Institute of High Current Electronics (Russian Federation) • Tomsk State University (Russian Federation) • Tomsk Polytechnic University (Russian Federation) • Siberian Physical Technical Institute (Russian Federation) • General Physics Institute (Russian Federation)

Sponsored by

Leningrad Laser Systems (Russian Federation) • Young Scientists Council IAO SB RAS (Russian Federation) - TOPAZ Research and Inculcation Enterprise (Russian Federation) • SP Equipment (Russian Federation) - LOTIS TIl (Belarus) - Special Systems Photonics (Russian Federation) - Azimut Photonics (Russian Federation) - Crystaltechno Ltd. (Russian Federation) Russian Academy of Sciences (Russian Federation)

Published by

SPIE

Volume 11322 
The papers in this volume were part of the technical conference cited on the cover and title page. Papers were selected and subject to review by the editors and conference program committee. Some conference presentations may not be available for publication. Additional papers and presentation recordings may be available online in the SPIE Digital Library at SPIEDigitalLibrary.org.

The papers reflect the work and thoughts of the authors and are published herein as submitted. The publisher is not responsible for the validity of the information or for any outcomes resulting from reliance thereon.

Please use the following format to cite material from these proceedings:

Author(s), "Title of Paper," in XIV International Conference on Pulsed Lasers and Laser Applications, edited by Victor F. Tarasenko, Anton V. Klimkin, Maxim V. Trigub, Proceedings of SPIE Vol. 11322 (SPIE, Bellingham, WA, 2019) Seven-digit Article CID Number.

ISSN: 0277-786X

ISSN: 1996-756X (electronic)

ISBN: 9781510634114

ISBN: 9781510634121 (electronic)

Published by

SPIE

P.O. Box 10, Bellingham, Washington 98227-0010 USA

Telephone +1 3606763290 (Pacific Time) · Fax +1 3606471445

SPIE.org

Copyright (c) 2019, Society of Photo-Optical Instrumentation Engineers.

Copying of material in this book for internal or personal use, or for the internal or personal use of specific clients, beyond the fair use provisions granted by the U.S. Copyright Law is authorized by SPIE subject to payment of copying fees. The Transactional Reporting Service base fee for this volume is $\$ 21.00$ per article (or portion thereof), which should be paid directly to the Copyright Clearance Center (CCC), 222 Rosewood Drive, Danvers, MA 01923. Payment may also be made electronically through CCC Online at copyright.com. Other copying for republication, resale, advertising or promotion, or any form of systematic or multiple reproduction of any material in this book is prohibited except with permission in writing from the publisher. The CCC fee code is $0277-$ $786 \mathrm{X} / 19 / \$ 21.00$.

Printed in the United States of America by Curran Associates, Inc., under license from SPIE.

Publication of record for individual papers is online in the SPIE Digital Library.

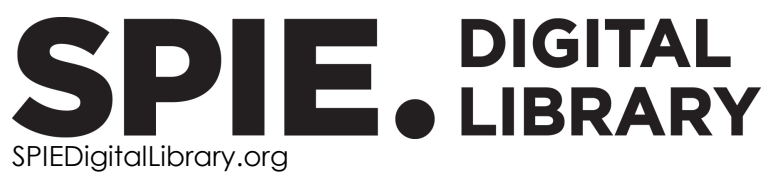

Paper Numbering: Proceedings of SPIE follow an e-First publication model. A unique citation identifier (CID) number is assigned to each article at the time of publication. Utilization of CIDs allows articles to be fully citable as soon as they are published online, and connects the same identifier to all online and print versions of the publication. SPIE uses a seven-digit CID article numbering system structured as follows:

- The first five digits correspond to the SPIE volume number.

- The last two digits indicate publication order within the volume using a Base 36 numbering system employing both numerals and letters. These two-number sets start with $00,01,02,03,04$, 05, 06, 07, 08, 09, 0A, OB ... 0Z, followed by 10-1Z, 20-2Z, etc. The CID Number appears on each page of the manuscript. 


\title{
Contents
}

\author{
xi Authors \\ xv Conference Committee \\ xix Introduction
}

PLENARY SESSION

1132202 A database of fluorescence spectra of crude oil of the Absheron peninsula registered by KA-14 LIDAR developed at the National Aviation Academy of Azerbaijan (Invited Paper) [11322-10]

1132203 Power supplies dedicated to the efficient control of the excimer lamps power (Invited Paper) [11322-17]

\section{AMPL SCHOOL}

1132204 Measurement of the duration of a femtosecond laser pulse during propagation in the atmosphere [11322-21]

$1132205 \quad$ Nonlinear optical properties of nanoparticles prepared via pulsed laser ablation [1 1322-63]

1132206 Fluorescence analysis of Bisphenol A photolysis under exposure to excilamps [11322-115]

1132207 The role of photochemical transformations of tetrahydrobiopterin in the pathogenesis and phototherapy of vitiligo [11322-119]

1132208 Optical amplification and laser generation in $\mathrm{LiCa}_{1-\mathrm{x}} \mathrm{Sr}_{\mathbf{x}} \mathrm{AlF}_{6}$ solid solutions doped with $\mathrm{Ce}^{3+}$ ions [11322-122]

1132209 Imaging by means of the bistatic laser monitor [11322-107]

$113220 \mathrm{~A}$ The calculation of the characteristics of the air refractive index fluctuations along line of sight for multiconjugated adaptive optics [11322-108]

$11322 \mathrm{OB}$ Sensor to register the optical distortions in the wide field of view of solar telescope [11322-89]

11322 OC Photophysical properties of europium salts with excitation in UV and visible-light range [11322-32]

11322 OD The influence of water and temperature on complexes of lanthanides with 6,6'Bis(diphenylphosphinoyl)-2,2'-bipyridyl [11322-30] 
11322 OE Optical characteristics of natural water samples collected in 2015-2017 in the supralittoral zone of the Alaid Volcano, the Kuril Islands [11322-1]

\section{GAS AND PLASMA LASERS, METAL VAPOR LASERS}

11322 OF Super-atmospheric $\mathrm{CO}_{2}$ laser with pulse repetition rate up to $2 \mathbf{~ k H z}$ [11322-51]

11322 OG Effect of the induction copper-vapor laser scaling on the output characteristics [11322-48]

$11322 \mathrm{OH} \quad$ Quantum-optical effects of resonant short laser pulse interaction with neon nanosecond discharge plasma in narrow shielded tubes [11322-25]

$11322 \mathrm{Ol} \quad$ Super-atmospheric pressure $\mathrm{CO}_{2}$ lasers with duration of radiation pulses less than 10 nanoseconds and pulse repetition rates up to $20 \mathrm{~Hz}$ [1 1322-52]

11322 0J Role of ozone in cryogenic plasma of carbon monoxide laser [11322-14]

11322 OK Characteristics of copper vapor laser output with radiation power 30-100 W [11322-79]

PHOTONICS OF OPTICAL MATERIALS, OPTOELECTRONICS

$11322 \mathrm{OL} \quad$ Study of spectral and fluorescent properties of different samples of humic acids [11322-27]

$11322 \mathrm{OM}$ Fabrication and characterization of highly transparent $\mathrm{Fe}^{2+}: \mathbf{M g A l}_{2} \mathrm{O}_{4}$ ceramics [11322-103]

$11322 \mathrm{ON} \quad$ Operating speed measurement of photodetector based on GaSb/GalnAsSb/GaAlAsSb heterostructure with frontal bridge contact for detecting ultrashort pulses at wavelengths of 1.55 and 1.9 um [1 $1322-1111]$

1132200 Solvent effect in the theoretical absorption and emission spectra of fluorescein dyes [11322-29]

11322 OP Detectivity and dark current analysis for quantum dot photodetectors with Ge/Si [1 1322-90]

$113220 Q \quad$ Growth and investigation of optical properties and laser oscillations from ternary thiogallate crystals with laser active dopants [11322-12]

11322 OR Comparison of the characteristics of the light field in a one-dimensional photonic crystal with the harmonic dielectric constant obtained according to the theory of the perturbations and with the direct calculation [11322-34]

FEMTOSECOND LASER SYSTEMS

11322 OT Compressors of negatively chirped pulses with internal telescope [11322-91]

iv 
$11322 \mathrm{OU} \quad$ Formation of few-cycle femtosecond pulses by phase compensated spectral broadening in media with alternating cubic nonlinearity sign [1 1322-43]

11322 OV Study of the temperature effect on the laser amplification process [1 1322-70]

11322 OW Regularities of nanosecond laser filamentation in the visible and near IR range of wave range (532 and $1562 \mathrm{~nm}$ ) in a medium with strong optical nonlinearity [11322-124]

$113220 \mathrm{X}$ Influence of phase and amplitude distortions of initial beam profile on the characteristics of filamentation domain [1 1322-105]

\section{LASER SYSTEMS, NEW LASER, OPTICAL TECHNOLOGIES, LASER APPLICATIONS}

$113220 Z$ Chirped-pulse erbium-doped all-fiber ultrashort pulse laser for a fiber optic Raman distributed temperature sensor [11322-18]

1132210 Situation and prospect of light and miniature UAV-borne LiDAR [1 1322-20]

1132211 Caustic of Gaussian laser beam with field phase random distortions [11322-36]

1132212 Dynamics of population of gadolinium-156 nuclei energy levels during neutron pumping of isotope-modified gadolinium oxide [11322-39]

1132213 Obtaining of micro-powder coatings from Fe-Ni and Fe-Cr alloys by pulse-periodic laser action [11322-40]

$1132214 \quad$ Vortex beam formation by means of control of the piston shift of a fiber array [11322-41]

1132215 Application of a scanning polarization lidar for the investigation of the particle orientation in cirrus clouds [11322-42]

1132216 Some aspects of optimizing the power of a real heat engine [1 1322-46]

1132217 Dynamic characteristics of a laser system for controlling an object's impact [11322-47]

1132218 The features of vanadium oxide nanostructures synthesized by laser ablation of metal in water [1 1322-50]

1132219 Optical properties of zinc oxide nanoparticles synthesized in plasma discharge in liquid under ultrasonic cavitation [11322-56]

$113221 \mathrm{~A} \quad$ Application of optical spectroscopy for study of hydrogen synthesis in plasma discharge in liquid under ultrasonic cavitation [11322-57]

11322 1B Thermal state of the package of cooled gas-dynamic microlasers [11322-58] 
$113221 \mathrm{C}$ Application of methods for analyzing images of nanoparticles in transmitted light to study their properties [11322-59]

11322 1D Laser fragmentation of photocatalyst particles based on bismuth silicates [11322-62]

$113221 \mathrm{E} \quad$ Effect of the $\mathrm{pH}$ of iron oxide nanoparticles solution on the rate of fibrin gel formation (according to light scattering data) [11322-67]

$11322 \mathrm{lF} \quad$ Current state of research in precision microprocessing and some of their applications [11322-71]

$113221 G$ Effect of the Apadent Pro gel on the mineralization of tooth enamel according to the laser spectroscopy [11322-76]

$113221 \mathrm{H} \quad$ Fiber optic laser cutting of carbon plastics [11322-77]

$1132211 \quad$ Comparative mechanisms of laser glass cutting [11322-78]

$113221 \mathrm{~J} \quad$ Prototype of laser gas analyzer of differential absorption technique for track measurements in urban conditions on the basis of Ce:LiCaAlF 6 laser [11322-121]

$113221 \mathrm{~K}$ Solid state tunable ultraviolet lasers based on fluoride crystals [11322-84]

$113221 \mathrm{~L} \quad$ Growing LiCAF crystal with 3 at\% $\mathrm{Cr}^{3+}$ and studying its properties [1 1322-88]

$113221 \mathrm{M}$ Regional manifestations of storm meteorological phenomena in the atmosphere and ionosphere [11322-92]

$113221 \mathrm{~N} \quad$ Numerical optimization of the dual-wavelengths copper vapor laser treatment of basal cell cancer [11322-93]

$1132210 \quad$ Lidar observation of aerosol dynamics in troposphere [11322-95]

11322 iP Plasma antennas formed in a Ge crystal under laser irradiation [11322-96]

$113221 Q$ Changing the aromaticity properties of small organic molecules after the ionization [11322-97]

11322 IR Mathematical modeling and experimental studies of thermal protection of composite materials under high-intensity effects of laser radiation [1 1322-98]

11322 is Luminescent properties of ZnO nanoparticles doped with W obtained in plasma discharge in liquid under ultrasonic cavitation [11322-104]

$113221 \mathrm{~T} \quad$ Lidar measurements of emission spectra of targets and aerosols excited by filamented femtosecond Ti:Sapphire laser pulses [11322-106]

$113221 \mathrm{U}$ The imaging of the welding processes with the use of CuBr-laser [11322-109] 
$113221 \mathrm{~V} \quad$ Use of optical methods of nondestructive control for diagnostics of damage sources of turbojet engine blades [11322-110]

11322 IW Eye-safe micro-pulse lidar on an 808nm laser diode [11322-112]

$113221 \mathrm{X} \quad$ Use of longwave remote sensing for aerosol research [11322-114]

$113221 \mathrm{Y}$ Interaction of aluminum oxide nanoparticles with human blood plasma thrombin (according to light scattering) [11322-116]

$1132212 \quad$ Lidar model for search of residual amounts of heavy hydrocarbons [1 1322-118]

1132220 Research on fluorescence and combination scatter of hydrocarbons [1 1322-83]

1132221 Investigation of laser ablation destruction of polymer materials [11322-125]

NONCOHERENT UV AND VUV-RADIATION SOURCES

1132222 Features of the formation of barrier discharge in xenon excimer lamps [11322-33]

1132223 Model of the pulsed periodic discharge in Ar-S2 mixtures [11322-2]

1132224 Possible degradation problems of lithium-tetraborate-based luminophores in cathodoluminescent UV-radiation sources [1 1322-86]

1132225 Apokamp discharge as a laboratory analogue of the transient luminous events of middle atmosphere [11322-3]

1132226 Photoregulation of agricultural plant growth and development by XeCl-excilamp [1 1322-5]

1132227 A new excimer lamp model of Institute of High Current Electronics [11322-4]

\section{CONVERSION OF LASER RADIATION, OPTOELECTRONIC DEVICES, NONLINEAR OPTICS}

1132228 Damage threshold of GaSe-type layered crystals under IR laser pulse radiation [1 1322-11]

1132229 Popular nonlinear optical crystals as down-converters of intense laser radiation and materials for millimeter wave applications [11322-102]

11322 2A The role of avalanche ionization in generation of defects in lithium fluoride crystals under the action of femtosecond laser pulses [11322-101]

$113222 B \quad$ THz emission efficiency in femtosecond laser-induced filament under different pumping conditions [11322-68] 
11322 2C Generation of THz emission in nonlinear BBO crystal at room temperature [1 1322-100]

11322 2D Comparison of terahertz radiation spectra emitted from single-color IR and UV filaments [11322-13]

$113222 \mathrm{E} \quad$ Optical detection of femtosecond laser pulses in a ferromagnet as a result of its magnetization by the magnetic field of the laser pulse [11322-38]

11322 2F Terahertz nonlinear waveguide-antenna driven by a femtosecond laser [11322-37]

$113222 \mathrm{G} \quad$ A comparative study of anti-Stokes shift under stimulated Rayleigh-Mie scattering in suspensions of $\mathrm{Ag}$ nanoparticles obtained in plasma discharge in liquid under ultrasonic cavitation [11322-60]

$113222 \mathrm{H}$ Determination of the parameters of associates in dimethylformamide using stimulated lowfrequency Raman scattering [11322-65]

\section{BIOPHOTONICS}

$1132221 \quad$ The study of changes of Young's modulus in disorganization of the collagen structures by optical coherence elastography [11322-55]

$113222 \mathrm{~J} \quad$ The study of paraffin-embedded tissue using multiphoton microscopy [11322-53]

$113222 \mathrm{~K}$ The influence of photosynthetic photon flux density and different photoperiods on optical density of Chlorella suspension [11322-99]

$11322 \mathrm{~L}$ Visualization of the effectiveness of the surface blocking of electrochemical sensors using laser confocal microscopy [11322-61]

$113222 \mathrm{M}$ Indirect action of VUV radiation on micro-organisms [11322-26]

$113222 \mathrm{~N}$ The impact of photoactivation on the antibacterial effect of nanoparticles obtained by pulsed laser ablation [1 1322-16]

1132220 Influence of laser acupuncture on EEG characteristics [11322-54]

$113222 \mathrm{P} \quad$ Presowing treatment of wheat seeds with UV radiation of XeCl excilamps [11322-82]

$113222 \mathrm{Q}$ The hardware model of extended photodynamic visualization for differentiation of the lymphatic pathways of closely located organs [1 1322-123]

\section{GAS DISCHARGES FOR LASERS AND NONCOHERENT RADIATION SOURCES}

$113222 \mathrm{R}$ Cumulation effect of an electron beam generated in a high-voltage nanosecond discharge plasma in vacuum and gas diodes [11322-22] 
$113222 \mathrm{~S} \quad$ ArF*, KrF*, and Fl lasers pumped by double discharge from generator with semiconductor opening switch [11322-19]

$113222 \mathrm{~T} \quad$ Optical radiation of the plasma flow in an arcjet thruster [11322-45]

$113222 \mathrm{U}$ Radiation in diamond, leucosapphire, and quartz under the excitation of electron beam with an energy of up to $400 \mathrm{keV}$ [11322-81]

$113222 \mathrm{~V} \quad$ Runaway electrons and $\mathrm{x}$-ray emission in air and other gases during discharges with long rise time of voltage pulses [1 1322-6]

11322 2W Conversion of propane-butane fraction into arenes on MFI zeolites activated by diffuse discharge plasma [11322-15]

\section{CARBON MATERIALS IN QE}

$113222 X \quad$ Raman spectroscopy of natural and synthetic diamonds [11322-120] 
Proc. of SPIE Vol. 11322 1132201-10

Downloaded From: https://www.spiedigitallibrary.org/conference-proceedings-of-spie on 26 Apr 2023 Terms of Use: https://www.spiedigitallibrary.org/terms-of-use 


\section{Authors}

Numbers in the index correspond to the last two digits of the seven-digit citation identifier (CID) article numbering system used in Proceedings of SPIE. The first five digits reflect the volume number. Base 36 numbering is employed for the last two digits and indicates the order of articles within the volume. Numbers start with 00, 01, 02, 03, 04, 05, 06, 07, 08, 09, OA, OB...0Z, followed by 10-1Z, 20-2Z, etc.

\author{
Abakarov, S.I., $1 \mathrm{G}$ \\ Adamson, S. O., 10, 1Q \\ Aglyamov, R. D., $1 \mathrm{~L}$ \\ Akhmedova, Z. R., 1G \\ Aksenov, V.P., 14 \\ Alekseev, S. V., 2A, 2B \\ Allahverdiyev, Kerim R., 02, 0Q, 28 \\ Ambrozevich, S. A., IF \\ Ancellet, Gerard, IW \\ Andreev, Igor A., ON \\ Andreev, Yury M., 29, 2C \\ Andrienko, O. S., 17, 1F, 1O, 1Q \\ Andrusenko, Yury N., IN \\ Anikin, Leonid P., OE \\ Apeksimov, Dmitriy V., OW, OX, 1T, 1V \\ Arakelyan, S. M., 17 \\ Ashurbekov, N. A., $\mathrm{OH}$ \\ Asratyan, A. A., 17, 1F, 10 \\ Astafurova, Tatyana P., 26 \\ Atuchin, V. V., 14 \\ Avdeev, Sergey M., 27 \\ Averyushkin, A. S., 17, $1 \mathrm{G}$ \\ Avtaeva, Svetlana V., 23 \\ Babushkin, P. A., 04, 0W, 0X, $1 \mathrm{~T}$ \\ Baghirov, Yashar M., 02 \\ Baksht, Evgenii Kh., 25, 2 V \\ Balin, Yury S., 15, 1W \\ Batenin, Vycheslav M., OG \\ Batov, Daniil T., ON \\ Bedenko, Sergei $V_{\text {., }} 12$ \\ Belik, Yulia A., 1D \\ Bobina, N. S., 2A \\ Bobrovnikov, S. M., $1 \mathrm{~L}$ \\ Bocharnikova, E. N., 06 \\ Bodryshev, Valery V., IC \\ Bogachev, N. N., IP \\ Borchevkina, O.P., 1M, 10 \\ Borisov, Aleksey V., 2I, 2J, 20 \\ Borisova, Nataliya E., OC, OD \\ Borodina, Tatyana I., 18 \\ Borovoi, A. G., 15 \\ Buchanov, Vladimir V., 11 \\ Buglak, Andrey A., 07 \\ Bukhtsooj, O., 2A \\ Bulychev, Nikolay A., 19, 1A, 1B, 1C, 1E, \\ $1 R, 1 S, 1 Y, 2 G$ \\ Burachenko, Alexander G., 2R, 2V \\ Bureev, Artem, 2Q \\ Burenina, Anastasia A., 2P
}

\author{
Burkhanov, I. S., 1E, 1Y \\ Burnashov, A. V., 04 \\ Chaidonova, V. S., 06 \\ Chaikov, L. L., 1E, 1Y \\ Charyshnikova, Zinaida, OC \\ Chernutsky, Anton O., $\mathrm{OZ}$ \\ Chubarenko, B. V., $1 \mathrm{M}$ \\ Chudinova, Yulia $\vee ., 26$ \\ Chuprakov, S. A., OB \\ Danilkin, M. I., 1S, 24 \\ Denisov, Lev K., $0 Z$ \\ Diatlov, Alexander V., 2R \\ Diez, R., 03 \\ Dikman, Ekaterina, $2 Q$ \\ Do, Quang Manh, Ol \\ Domnin, D. A., $1 \mathrm{M}$ \\ Donodin, Alexander I., ON \\ Douhan, Rahaf M. H., OP \\ Dresvyanskiy, V. P., 2A \\ Drevolsky, A. S., 00 \\ Dudorov, V. V., 14 \\ Dvoretskiy, Dmitriy A., OZ \\ Dyachkovsky, Denis A., OG \\ Dyakov, Y. A., 1M, 10, $1 Q$ \\ Dzhalilova, S., 2W \\ Enkhbat, Sodnom, 2A \\ Erofeev, Michail V., 2U, 2W \\ Erofeev, V., 2W \\ Erokhin, Alexandr I., 16, 2G \\ Evstigneev, V. L., 17 \\ Evstyunin, G. A., 17 \\ Evtushenko, Gennady S., 09 \\ Fakhrutdinova, Elena D., 05, 1D \\ Farat, O., OD \\ Filatova, S. A., $1 \mathrm{P}$ \\ Formalev, Vladimir F., 1B \\ Frolov, Stanislav A., OU \\ Galkin, A. F., 17 \\ Garelina, Svetlana A., OK, 1H \\ Genin, D. E., 2X \\ Gerasimova, M. A., 00 \\ Gerke, M. N., 17 \\ Gol'tsova, Polina A., 26 \\ Golubkov, G. V., 10, 1Q \\ Golubkov, M. G., 10, $1 Q$ \\ Gomez, J., 06 \\ Gomez, M., 06 \\ Goncharova, D. A., 2N \\ Gorbunkov, V., 2T
}


Grachev, Gennadiy N., 13

Grigoryants, Alexander G., OK, 1H

Grinevich, V. A., 2T

Grudtsyn, Ya. V., 2D

Gubanova, D. P., 10, 1Q

Gulyamova, Elmira S., OM

Guo, Wenju, 10

Gusein-zade, N. G., IP

Huseynov, Illkin T., OQ

Iglakova, A. N., 04

Il'ichev, Nickolay N., OM

Iminov, K. O., $\mathrm{OH}$

Ionin, A. A., OJ, 2D

Ivanov, M. V., 2B

Ivashkin, P. I., 17

Jiang, Chenghao, 10

Jiang, Yan, 10

Kabanov, A. M., OW, OX, $1 \mathrm{~T}$

Kamynin, V. A., IP

Karapusikov, Alexey, $1 \mathrm{X}$

Karasik, Valeriy E., ON, OZ

Karpov, I. V., 1M, 10

Karpov, M. I., $1 M$

Karpukhin, Vyacheslav T., OG, 18

Kaufman, E. V., 00

Kazantsev, S. Yu., IP

Kazaryan, Mishik A., OG, OK, OR, 12, 16,

$17,18,19,1 \mathrm{~A}, 1 \mathrm{~B}, 1 \mathrm{C}, 1 \mathrm{E}, 1 \mathrm{~F}, 1 \mathrm{G}, 1 \mathrm{H}$,

$1 \mathrm{I}, 1 \mathrm{M}, 1 \mathrm{~N}, 1 \mathrm{O}, 1 \mathrm{1Q}, 1 \mathrm{R}, 1 \mathrm{~S}, 1 \mathrm{Y}, 20,24$,

$2 \mathrm{E}, 2 \mathrm{~F}, 2 \mathrm{G}, 2 \mathrm{H}$

Kazaryan, Serine M., 1F, $1 Q$

Kharcheva, Anastasiia $V ., 0 C, O D$

Kharitonov, Dmitriy A., OC, OD

Khomyakov, Maksim N., 13

Kinyaevskiy, I. O., OJ

Kirichenko, M. N., 1E, 1Y

Kirpichnikov, Anatoliy $V_{\text {., }}$ OV

Kirtsidely, Irina Yu., $2 M$

Kiselev, A. V., OA

Kislov, V. I., 11

Kistenev, Yury V., 2I, 2J, 20

Klemasheva, M. G., 15

Klimachev, Yu. M., OJ

Klimkin, Anton V., 1V, 1X, 1Z, 20, 2Q

Klyuchareva, Svetlana V., $1 \mathrm{~N}$

Knyazkova, Anastasia I., 2I, 2J, 20

Knyshev, Vladimir V., 12

Kokhanenko, Andrey P., OP

Kokhanenko, Grigory P., 15, 1W, 1X, 1Z, 20

Kolesnik, Sergey A., 1B, 1R

Kolobov, D. YU., OA

Kolosov, V. V., 14

Konovalov, Gleb G., ON

Kopylov, E. A., OA

Korableva, S. L., IK

Koribut, A. V., 2D

Kosareva, O. G., 2D

Kotkov, A. A., OJ

Kovadlo, P. G., OA, OB

Kozlov, A. Yu., OJ
Kozlov, B. A., OF, Ol

Kraiski, Aleksandr V., OR

Kraiski, Anton A., OR

Krasovskii, V. I., $1 \mathrm{~F}$

Kritsky, Mikhail S., 07

Kuchinskaya, O. I., OW

Kudlatskaya, Anastasia A., OL

Kudryavtseva, Anna D., 2H

Kulinich, S. A., 2N

Kuptsov, Gleb V., OV

Kurbangadzhieva, M. B., $\mathrm{OH}$

Kurdyaeva, Y. A., 1M

Kurnosov, A. K., OJ

Kuryak, Aleksey N., 1V, 1X, 1Z, 20, 2Q

Kuznetsov, A. V., 2A

Kuznetsov, Vladimir S., 25

Lanskii, Grigory V., 29, 2C

Lapin, Ivan N., 05, 2L

Laptev, Alexey V., OV

Lazarev, Vladimir A., ON

Letova, Elizaveta Yu., 22, 2M

Levitsky, M. E., 14

Li, Hongda, IF

Lipatov, Evgeniy I., 2P, 2U, 2X

Liu, Ruqing, 10

Lokhin, Aleksey A., 2I

Lomaev, Mikhail I., $2 \mathrm{R}$

Losev, V. F., 2A, 2B, 2C

Lozovoy, Kirill A., OP

Lubenko, D. M., 2B, 2C

Lukinova, Elena $\mathrm{V} ., 07,1 \mathrm{~L}$

Lukyashin, Konstantin E., OM

Lunina, Olga N., OE

Lyabin, Nikolay A., OG, OK, 1F, $1 \mathrm{H}$

Lyasheva, Lydmila $\vee$., 26

Machs, Eduard M., 2M

Madirov, Eduard I., 07, 08

Mai, The Nguyen, 0 I

Makaryan, A. H., 2E

Maksimov, Roman N., OM

Malikov, Mikhail M., 0G, 18

Mamrashev, Alexander A., 29

Mariage, Vincent, IW

Marisov, M. A., $1 \mathrm{~K}$

Markelov, Aleksey A., 2J, 20

Martynovich, E. F., 2A

Matvienko, G. G., 04, OW, 0X, $1 T$

Mayer, Georgiy V., OL

Mirochnichenko, Maxim B., 2J

Mironova, Tatiana $\mathrm{V} ., 2 \mathrm{H}$

Miroshnichenko, Maksim B., 20

Mityagin, YU. A., 2D

Mkhitaryan, R. G., IF

Mkrtychev, O. V., 21

Mokrousova, D. V., OJ, 2D

Morozova, Elena A., OK, 1F, $1 \mathrm{H}$

Murcia, M., 06

Musayev, Aydin A., 02

Nam, Irina, $2 Q$

Nasonov, S. V., 15 
Naumov, Alexander K., 1K, $1 \mathrm{~L}$

Nemoykina, A. L., 2N

Nepomnyashiy, A. S., $1 U$

Nikoghosyan, A. S., 2E, 2F

Nikolaev, Nazar, 29, 2C

Nikolaev, Victor V., 2J

Nizamutdinov, Alexey S., 07, 08, 1 J, 1K, 1L

Novoselov, M. M., 15

Obhodskiy, A. V., 1 Z

Obkhodskaya, Elena V., 1Z, 20

Obkhodskiy, Artem $\vee ., 20$

Ofitserov, E. N., 11

Oleshko, Vladimir I., $2 U$

Olkhov, O. A., 10

Orekhov, llya O., OZ

Oshlakov, V. K., 04, 0W, 0X, $1 T$

Osipov, A. V., 17

Osipov, Konstantin, $1 \mathrm{X}$

Osipov, Vladimir V., OM

Ososkov, Yan Zh., $\mathrm{OZ}$

Ozol, D. I., 24

Palianov, P. A., $1 \mathrm{~L}$

Panarin, Victor A., 25, 26, 27

Panchenko, Alexei N., $2 S$

Panchenko, YU. N., $1 \mathrm{~L}$

Panov, N. A., 2D

Pashayev, Arif M., 02, 0Q, 28

Pashinin, Pavel P., OM

Patsaeva, Svetlana V., OC, OD, OE

Payurov, A. Ya., OF, Ol

Pechenitsin, Dmitrii S., 25

Pelon, Jacques, IW

Penner, loganes E., 15, 1W, 12

Pestryakov, Efim V., OV

Petrov, A. V., OW, OX, $1 T$

Petrov, D. V., $2 X$

Petrov, Victor $\mathrm{V}$., OV

Petrov, Vladimir A., OV

Petukhov, T. D., 14

Pinaev, Pavel A., 13

Piquet, H., 03

Pnev, Alexey B., 0 Z

Podlesnykh, S. V., IP

Ponomarev, Igor $V_{\text {., }} 1 \mathrm{~N}$

Ponomarev, Yury, $1 \mathrm{X}$

Prok, Irina A., 26

Prokopev, V. E., 2B

Pushkareva, Aleksandra E., IN

Rabinskiy, Lev N., $1 \mathrm{R}$

Rakhimov, Niyaz F., 08, $1 \mathrm{~J}$

Rashidov, Vladimir A., OE

Revenko, Valery I., 11

Ripenko, $V ., 2 W$

Rizaev, G. E., 2D

Rogalin, V. E., IP

Rogova, A. V., 00

Romanenko, Sofia S., $2 \mathrm{~K}$

Romanovsky, O. A., OW

Roshdestvensky, A. E., 16

Rueda, V., 03
Russkih, I. V., OA

Sachkov, Victor I., OK, 1F, 1H, 1I, 1Z, 20

Sadikhov, Ilham Z., 02, 0Q, 28

Sadovnikov, S. A., OW

Salayev, Eldar Yu., 28

Samoilova, S. V., 15

Sandabkin, E. A., 2C

Sandykova, Ekaterina A., 21

Saraev, Yu N., $1 \mathrm{U}$

Savelyev, Egor S., 05

Savinov, S. A., 2D

Sazonkin, Stanislav G., $\mathrm{OZ}$

Seleznev, L. V., 2D

Selyanina, Svetlana B., OL

Selyukov, A. S., 24

Semashko, Vadim V., 07, 08, 1J, 1K, $1 \mathrm{~L}$

Semenchuk, V. M., $1 \mathrm{U}$

Shabalina, Anastasiia V., $2 \mathrm{~L}$

Shakhsinov, G. Sh., OH

Shakirov, Ainur A., 08, $1 \mathrm{~L}$

Shalay, Victor V., 2T

Shamanayev, V.S., 1 Z

Shamanin, Igor $V_{\text {., }} 12$

Shamanin, Vitaly I., 12

Shamanskaya, E. L., 17

Shao, Tao, 2V

Shapovalov, V. L., 10

Sharko, Daria O., 2L

Shavelev, Alexey A., 08, 1J, 1K, $1 \mathrm{~L}$

Shemanin, Valerii G., 21

Sheshin, E. P., 24

Shevchenko, Mikhail A., 2H

Shevtsov, Yu. V., 21

Shiganov, Igor N., OK, $1 \mathrm{H}$

Shikhovtsev, A. YU., OA, OB

Shipilo, D. E., 2D

Shitov, Vladislav A., OM

Shokhrin, D. V., IP

Shulepov, Michail A., 2P

Shulmina, Polina $\vee ., 2 O$

Shuo, Zhang, $1 \mathrm{X}$

Shvydkoy, Dmitriy O., OT

Sidorin, Andrey $\mathrm{V}$., $\mathrm{OM}$

Sim, Elena S., 2l, 2J

Sinitsyn, D. V., OJ

Skakun, Victor S., 25, 26, 27

Slyusareva, Evgenia A., 0O, 2H

Smirnov, Aleksandr L., 13

Sokolova, Irina $V_{\text {., }}$ OL

Sokovikov, V. G., 1 Z

Solomonov, Vladimir I., OM

Sosnin, Eduard A., 25, 26, 27

Spirina, Lyudmila $\vee ., 2 J$

Statsenko, Pavel A., 13

Sumyanova, Ts., OD

Surnina, Elena N., 2P

Svetlichnyi, Valery A., 05, 1D, 2N

Tadevosyan, V. R., 2E

Tagiyev, Bahadur G., 02, 0Q, 28

Tagiyev, Ogtay B., $O Q$ 
Tarabrin, Mikhail K., ON

Tarasenko, Victor F., 25, 27, 2R, 2S, 2U, 2V, 2W

Tchaikovskaya, Olga N., 06, OL

Tcherniega, Nikolay $\mathrm{V}$., $2 \mathrm{H}$

Telegina, Taisia A., 07

Tikhonov, Egor V., OM

Tomilin, F. N., 00

Tonoyan, G. A., IF

Topchiy, Sergey B., iN

Trigub, Maxim V., 09, 1U, 1V

Trikshev, A. I., IP

Trofimchuk, Oksana A., 2K

Trufanov, V. O., $2 \mathrm{~N}$

Trunov, Vladimir I., OT, OU

Tsvetkov, V. B., IP

Tumorin, Viktor $V_{\text {., }} \mathrm{OM}$

Turanov, Sergey B., 2K

Valiano, Georgiy E., 18

Vasiliev, P. A., 1M

Vasnev, Nikolai A., 09, $1 \mathrm{U}$

Vechtomova, Yuliya L., 07

Veliyev, Nazim A., 02

Vereschagina, N. YU., 1S, 24

Viktorova, Irina A., 26

Vlasov, Dmitrii S., ON

Vodyankin, Andrey A., 1D

Vodyankina, Olga V., ID

Voropaev, Vasilii S., ON

Wang, Chunxiao, 10

Xie, Tianpeng, 10

Yakovlev, Alexey N., 2K

Yakovlev, S. V., OW

Yakovlev, Yury P., ON

Yan, Ping, 2V

Yarullin, Linar R., $1 \mathrm{~J}$

Yastrebkov, A. B., Ol

Yelisseyev, A. P., $2 X$

Yezekyan, T. S., 2E

Zakharyan, R. A., 17

Zaripov, A. R., $2 X$

Zemlyanov, A. A., OW, OX, $1 T$

Zemlyanov, Al. A., OW

Zhang, Cheng, $2 \mathrm{~V}$

Zhiltsova, Anna A., OE

Zhirnova, S. V., 17

Zhitov, M. YU., $1 G$

Zhluktova, I. V., IP

Zhu, Jingguo, 10

Zuev, Maxim S., $1 \mathrm{~J}$

Zvereva, Galina N., 22, $2 \mathrm{M}$ 


\title{
Conference Committee
}

\author{
Conference Chairs
}

Victor F. Tarasenko, Institute of High Current Electronics

(Russian Federation)

J. Gary Eden, University of Illinois (United States)

\section{Program Committee}

Victor F. Tarasenko, Institute of High Current Electronics

(Russian Federation)

J. Gary Eden, University of Illinois (United States)

Maxim V. Trigub, Institute of Atmospheric Optics (Russian Federation)

Mikhail V. Erofeev, Institute of High Current Electronics

(Russian Federation)

Anton V. Klimkin, Institute of Atmospheric Optics (Russian Federation)

Yuri S. Akishev, Troitsk Institute for Innovation and Fusion Research - TRINITI (Russian Federation)

Kerim R. Allahverdiev, National Aviation Academy (Azerbaijan)

Yury M. Andreev, Institute of Monitoring of Climatic and Ecological System (Russian Federation)

Pyotor A. Bokhan, Institute of Semiconductor Physics (Russian Federation)

Gennadiy D. Chebotarev, Southern Federal University

(Russian Federation)

Gennadiy S. Evtushenko, Federal Research Centre for Projects Evaluation and Consulting Services (Russian Federation)

Andrey A. Ionin, P. N. Lebedev Physical Institute (Russian Federation)

Mishik A. Kazaryan, P. N. Lebedev Physical Institute (Russian Federation)

Tatyana N. Kopylova, Siberian Physical Technical Institute (Russian Federation)

Ivan B. Kovsh, Laser Association (Russian Federation)

Vitaliy I. Krasovskiy, General Physics Institute (Russian Federation)

Lacour Bernard, Université Paris-Sud (France)

Valery F. Losev, Institute of High Current Electronics (Russian Federation)

Gennady G. Matvienko, Institute of Atmospheric Optics

(Russian Federation)

Georgy V. Mayer, Tomsk State University (Russian Federation)

Igor Meglinski, University of Oulu (Finland)

Marina A. Gerasimova, Siberian Federal University, (Russian Federation)

Vladimir V. Osipov, Institute of Electrophysics (Russian Federation)

Edward A. Sosnin, Institute of High Current Electronics (Russian Federation)

Alexander V. Voitsekhovskii, Tomsk State University (Russian Federation)

Piquet Hubert, University of Toulouse (France)

Alexander M. Razhev, Institute of Laser Physics (Russian Federation) 
Nicola V. Sabotinov, Institute of Solid State Physics (Bulgaria)

Tao Shao, Institute of Electrical Engineering (China)

Matvey B. Shpizel, Hyperboloid LLC (United States)

Anatoliy N. Soldatov, Tomsk State University (Russian Federation)

Andrei Starodoumov, Coherent Inc. (United States)

Alexey A. Trenkin, Russian Federal Nuclear Center - The All-Russian

Research Institute of Experimental Physics (Russian Federation)

Milan S. Trtica, Institute of Nuclear Sciences (Serbia)

Andreas Ulrich, Technical University of Munich (Germany)

Jochen Wieser, Excitech Ltd. (Germany)

Aleksey N. Yakovlev, Tomsk Polytechnic University (Russian Federation)

Olga N. Tchaikovskaya, Tomsk State University (Russian Federation)

Aleksander A. Zemlyanov, Institute of Atmospheric Optics

(Russian Federation)

Dmitriy E. Zakrevsky, Institute of Semiconductor Physics

(Russian Federation)

Local Committee

Maxim V. Trigub, Institute of Atmospheric Optics (Russian Federation)

Anton V. Klimkin, Institute of Atmospheric Optics (Russian Federation)

Mikhail E. Levitskiy, TOPAZ Research and Inculcation Enterprise (Russian

Federation)

Mikhail V. Erofeev, Institute of High Current Electronics

(Russian Federation)

Anna A. Simonova, Institute of Atmospheric Optics (Russian Federation)

Olga V. Nozdrina, Tomsk Polytechnic University (Russian Federation)

Ekaterina Yu. Dikman, Diagnostika LLC (Russian Federation)

Nikolay A. Vasnev, Institute of Atmospheric Optics (Russian Federation)

Dmitriy V. Apeksimov, Institute of Atmospheric Optics (Russian Federation)

Dmitriy E. Genin, Institute of High Current Electronics (Russian Federation)

Stanislav N. Torgaev, Tomsk State University (Russian Federation)

Yurii V. Kistenev, Siberian State Medical University (Russian Federation)

Evgeniy I. Lipatov, Institute of High Current Electronics

(Russian Federation)

\section{Session Chairs}

1 Plenary Session

Milan S. Trtica, Institute of Nuclear Sciences (Serbia)

Kerim R. Allahverdiev, National Aviation Academy (Azerbaijan)

Tao Shao, Institute of Electrical Engineering (China)

Vladimir V. Chvykov, Colorado State University (United states) 
2. AMPL School

Milan S. Trtica, Institute of Nuclear Sciences (Serbia)

Jochen Wieser, Excitech Ltd. (Germany)

3 Gas and Plasma Lasers, Metal Vapor Lasers

Mishik A. Kazaryan, Physical Institute (Russian Federation)

Anatoliy N. Soldatov, Tomsk State University (Russian Federation)

4 Photonics of Optical Materials, Optoelectronics

Olga N. Tchaikovskaya, Tomsk State University (Russian Federation)

Vladimir I. Solomonov, Institute of Electrophysics (Russian Federation)

5 Femtosecond Laser Systems

Aleksander A. Zemlyanov, Institute of Atmospheric Optics

(Russian Federation)

Valery F. Losev, Institute of High Current Electronics (Russian Federation)

6 Laser Systems, New Laser, Optical Technologies, Laser Applications

Gennadiy S. Evtushenko, Federal Research Centre for Projects Evaluation and Consulting Services (Russian Federation)

Zhu Jingguo, Institute of Microelectronics (China)

$7 \quad$ Non-coherent UV and VUV-Radiation Sources

Edward A. Sosnin, Institute of High Current Electronics (Russian Federation)

8 Conversion of Laser Radiation, Optoelectronic Devices, Nonlinear Optics

Valery A. Svetlichnyi, Tomsk State University (Russian Federation)

Kerim R. Allahverdiev, National Aviation Academy (Azerbaijan)

9 Biophotonics

Eduard A. Sosnin, Institute of High Current Electronics (Russian Federation)

Andrey M. Kabanov, Institute of Atmospheric Optics (Russian Federation)

10 Gas Discharges for Lasers and Non-coherent Radiation Sources

Victor F. Tarasenko, Institute of High Current Electronics

(Russian Federation)

Jochen Wieser, Excitech Ltd. (Germany)

11 Carbon Materials in QE (Round Table)

Evgenia S. Sheremet, Tomsk Polytechnic University (Russian Federation)

Evgeniy I. Lipatov, Institute of High Current Electronics

(Russian Federation) 
Proc. of SPIE Vol. 11322 1132201-18

Downloaded From: https://www.spiedigitallibrary.org/conference-proceedings-of-spie on 26 Apr 2023 Terms of Use: https://www.spiedigitallibrary.org/terms-of-use 


\title{
Introduction
}

The XIV International Conference on Atomic and Molecular Pulsed Lasers (AMPL) traditionally has been devoted to subjects such as physical and chemical processes in laser active media, new active media and pumping methods including discharges for lasers and non-coherent radiation sources, new lasers development technologies, fundamental issues of laser physics, applications of lasers in science, technology, medicine, the development of laser-based devices, and new optical technologies. One of the principal goals of the conference has been contiguity of fundamental and applied sciences. Therefore, much attention was paid to the application of new light sources in science, engineering, medicine, etc. Moreover, one of the important issues of the AMPL is to provide an opportunity for young scientists to present their work and to get feedback from scientists and specialists in the photonics area.

In 2019, the AMPL was dedicated to the 50th anniversary of Institute of Atmospheric Optics and Academic Science in Tomsk. The scientific program of the conference included the following sessions:

-Gas and Plasma Lasers, Metal Vapor Lasers;

-Photonics of Optical Materials, Optoelectronics;

-Biophotonics;

-Femtosecond Laser Systems;

-Laser Systems and New Laser and Optical Technologies, Laser Applications;

-Non-coherent UV and VUV-Radiation Sources;

-Conversion of Laser Radiation, Optoelectronic Devices, Nonlinear Optics;

-Gas Discharges for Lasers and Non-coherent Radiation Sources;

-Carbon Materials in Quantum Electronics.

\author{
Victor F. Tarasenko \\ Anton V. Klimkin \\ Maxim V. Trigub
}


Proc. of SPIE Vol. 11322 1132201-20

Downloaded From: https://www.spiedigitallibrary.org/conference-proceedings-of-spie on 26 Apr 2023 Terms of Use: https://www.spiedigitallibrary.org/terms-of-use 